\title{
Analysis of Routine Blood Profile as Data Supporting for Nursing Assessment in Breast Cancer Patients Undergoing Chemotherapy Treatment at the RSU. Dr. Wahidin Sudirohusodo
}

\author{
Yuliana Syam ${ }^{*}$, Prihantono ${ }^{2}$, Elly L Sjattar ${ }^{1}$, Arnis Puspitha1 \\ 1) Nursing Study Program, Nursing Faculty, Hasanuddin University \\ 2) Department of Medical Sciences, Faculty of Medicine, University Hasanuddin \\ yulianasyamuh@gmail.com \\ DOI: http://doi.org/10.29080/jhsp.v3i3S.301
}

\section{Keywords}

Blood Profil;

Breast Cancer;

Chemotherapy

\begin{abstract}
Chemotherapy is one of the modality therapies given to breast cancer patients to inhibit cancer cell metastases. The side effects of chemotherapy can suppress the hematopoietic system in the bone marrow and progressively affect the patient's prognosis. The aim of study was to analyze routine blood profiles as supporting data in developing nursing care for breast cancer patients undergoing chemotherapy at the RSU. Dr. Wahidin Sudirohusodo Makassar, Indonesia, from June to September 2018. This research was a descriptive research with descriptive survey method. This research was conducted at the RSU Surgical Polyclinic. Dr. Wahidin Sudirohusodo. The sampling technique used was Non-Probability Sampling a purposive sampling method. The participants of this study were patients with breast cancer who undergo chemotherapy treatment with a number of samples that meet the inclusion criteria as many as 32 people. of the 17 routine blood components which were assessed as one of the investigations in 32 patients were found to be 4 abnormal components, red blood cells mean $\pm S D\left(3.9910^{\wedge} 6 / u L \pm 0.51\right)$, hemoglobin mean $\pm S D(11.18 \mathrm{gr} / \mathrm{dl} \pm 1.09)$, hematocrit mean $\pm S D(34.96 \% \pm 3.96)$, and mean $\pm S D$ monocyte $\left(15,04310^{\wedge} 3 / u L \pm 8.95\right)$. due to metastasis and side effects of chemotherapy treatment decrease red blood cells, hemoglobin, hematocrit, and increase in specific immune response through increase of monocytes indicator that performing phagocytosis..
\end{abstract}

\section{Background}

WHO data in 2013 showed that there were more than 508,000 women predicting breast cancer mortality worldwide in 2011. GLOBOCAN data in 2008, although breast cancer was a disease in developed countries, it turned out that $50 \%$ of cases and $58 \%$ of deaths occurred in developing countries[1].

In Indonesia, the prevalence of cancer is also quite high. Based on data from the Basic Health Research (Riskesdas) in 2013, the prevalence of tumors/ cancer in Indonesia is 1.4 per 1000 population, or about 330,000 people[2]

Data on Hospital Information Systems (SIRS) in 2013 explained that the number of inpatients with carcinoma in all hospitals in Indonesia was 1.4 per 1000 population and constituted $5.7 \%$ of the causes of death from all diseases. Mammary carcinoma was recorded as the highest type of cancer in inpatients and outpatients care in all hospitals in Indonesia with a total of 12,014 patients or $28.7 \%$ followed by cervical cancer as many as 5,786 cases or $11.78 \%[3]$.

At present, the decision of the determination of therapy tends to lead to the molecular classification of breast cancer. Women diagnosed with breast or ovarian cancer will face with aggressive chemotherapy including treatment with drugs combination. This treatment can have an effect on quality of life or have side effects. Chemotherapy can cause nausea, vomiting, hair loss, cognitive dysfunction, fatigue, changes in sexual function, and decreased quality of life. The impact on fertility, premature menopause, and bone healthy is also another effect from chemotherapy of breast cancer patients.

Chemotherapy has beneficial effects on the prognosis of breast cancer, but on the other hand, it is feared could lead to side effects. Side effects of chemotherapy are bone marrow depression, diarrhea, hair loss, nausea, and other health problems. Anemia as a pathology response with neoadjuvand therapy and 
chemotherapy can affect the survival of the patient [4].

If these problems are not treated, they will cause further problems, like the disturbance of nutritional balance and will ultimately lead to a decrease in quality of life in cancer patients. Those are what causes the tendency of breast cancer sufferers to refuse chemotherapy or the chemotherapy cycle that has been scheduled to be interrupted before the therapy ends.

Examined the effect of chemotherapy on bone marrow in 274 gynecological cancers and 503 breast cancers[5]. Side effects on hematopoietic cells occur in $28.8 \%$ of patients and begin to occur at any time when the cycle of chemotherapy is given and the tendency to increase at the end of the cycle. The amount of erythrocyte, hemoglobin, neutrophil and platelet production will decrease and will reduce the ability of phagocytosis to cancer cells so that it worsens the prognosis. Hemoglobin, neutrophils and platelets can be used as a measure of hematopoietic cell conditions. Examined the side effects of cisplatin chemotherapy as a part of chemotherapy drugs and hematopoietic side effects based on hemoglobin, leukocytes and platelets[6]. These side effects begin to occur after the first cycle and were significant after the next cycle. So, the routine blood images can be a source of prognostic information and supporting data in nursing assessment that are important and can to predict clinical outcomes development of cancer metastases, including in developing nursing care.

The aim of nursing care is to identify client problems. The nursing process is one of the main approaches in providing nursing care which is a process of decision-making and problem-solving. After the application of the nursing process, nurses are required to have knowledge of concepts and theories as the basis for interpreting the data obtained.

\section{Methods}

This study used a descriptive analysis method in outpatient care Installation of RSU. Dr. Wahidin Sudirohusodo. Data processing included patient characteristics and routine blood analysis performed on 32 patients with ages ranging from 32 years to 68 years. The sample was a patient with a diagnosis of breast cancer who underwent chemotherapy at the RSU. Dr. Wahidin Sudirohusodo, from July to October 2018. Blood samples were taken at the polyclinic laboratory using EDTA (ethylenediaminetetraacetic acid). The sampling technique used was non-probability sampling with a purposive sampling method in breast cancer patients who underwent chemotherapy treatment with the number of samples that met the inclusion criteria as many as 32 people.

\section{Results}

This research was carried out from July to October 2018. The implementation of this research was in Outpatient Care Installation at Wahidin Sudirohusodo Hospital. The number of samples in this study was 32 people. The distribution of patient characteristics can be seen in the following table.

Table 1. Demographic Characteristics of Patients with Breast Cancer with Chemotherapy

\begin{tabular}{cc}
\hline Variable & $\mathbf{N}$ \\
\hline Age (years) & \\
(mean \pm SD) & $46.84 \pm 9176$ \\
Min-max & $32-68$ \\
Education Level & \\
Elementary & $4(12.5 \%)$ \\
Junior high School & $10(31.3 \%)$ \\
Senior High School & $13(40.6 \%)$ \\
College & $3(9.4 \%)$ \\
Not School & $2(6.3 \%)$ \\
Terms of Suffering(years) & \\
(mean \pm SD) & \\
Min - Max & $1.22 \pm 0.42$ \\
$1-3$ years & $1-7$ \\
$4-6$ years & 25 \\
Status & 7 \\
Married & \\
Divorced & \\
Not Married & $28(87.5 \%)$ \\
& $1(3.1 \%)$ \\
\hline
\end{tabular}


A total of 32 breast cancer patients who underwent chemotherapy, an average age of 46 years were still in the productive age range, based on the highest level of education graduated from high school (40.6 $\%)$, while the average long-suffering 1:22 year and the most long-suffering 1-3 years (78\%) and on the basis of marital status on average most patients were married $(87.5 \%)$.

Table 2. Distribution frequency of Routine Blood in Breast Cancer patients with Chemotherapy

\begin{tabular}{lrrcc}
\hline & Mean & \multicolumn{1}{c}{ SD } & $\begin{array}{c}\text { Reference } \\
\text { Values }\end{array}$ & Unit \\
\hline WBC & 7714 & 5.4069 & $4: 00-10.0$ & $10^{\wedge} 3 / \mathrm{uL}$ \\
RBC & 3.9957 & 0.51528 & $4: 00-6: 00$ & $10^{\wedge} 6 / \mathrm{uL}$ \\
HGB & 11,186 & 1.0987 & $12.0-16.0$ & $\mathrm{gr} / \mathrm{dL}$ \\
HCT & 34.96 & 3,491 & $37.0-48.0$ & $\%$ \\
MCV & 87.96 & 6077 & $80.0-97.0$ & $\mathrm{fL}$ \\
MCH & 28.21 & 2,347 & $26.5-33.5$ & $\mathrm{pg}$ \\
MCHC & 41.96 & 52.738 & $31.5-35.0$ & $\mathrm{gr} / \mathrm{dL}$ \\
PLT & 346.43 & 130,183 & $150-400$ & $10^{\wedge} 3 / \mathrm{uL}$ \\
RDW-CV & 15,543 & 2.6872 & $10.0-15.0$ & $\mathrm{fL}$ \\
PDW & 9,796 & 1.2808 & $10.0-18.0$ & $\mathrm{fL}$ \\
MPV & 9.35 & 0.6489 & $6.50-11.0$ & $\%$ \\
PCT & 0.3411 & 1,292 & $0.15-0.50$ & $\%$ \\
NUET & 49.5 & 17.8409 & $52.0-75.0$ & $\%$ \\
LYMPH & 31,821 & 11,0087 & $20.0-40.0$ & $10^{\wedge} 3 / \mathrm{uL}$ \\
MONO & 15,043 & 8,9535 & $2.00-8.00$ & $10^{\wedge} 3 / \mathrm{uL}$ \\
EO & 3,086 & 3.4497 & $1.00-3.00$ & $1 \wedge 3 / \mathrm{uL}$ \\
BASO & 0.7339 & 0.31974 & $0.00-0.10$ &
\end{tabular}

From the data component in Table 2. routine blood tests found in breast cancer patients with chemotherapy treatment, abnormalities can be seen from the decrease in the average value on RBC levels (3.9957 ) $10^{\wedge} 6 / \mathrm{uL}$; Hb level mean $(11,186) \mathrm{gr} / \mathrm{dL}$; hematocrit $(34.96) \%$; and an increase in monocyte levels $(15,043) 10^{\wedge} 3 / \mathrm{uL}$.

\section{Discussion}

Chemotherapy with a given regimen that belongs to the cytostatic group can cause a decrease in hematopoietic cells, especially hemoglobin[5]. Previous studies have identified anemia as an independent prognostic factor, which has a detrimental effect on survival in several types of cancer including breast cancer[7]. According to Zhu W (2015), the incidence of anemia before chemotherapy was associated with a poor pathological response to neoadjuvant therapy which has an impact on survival in breast cancer patients[4].

This study found that erythrocytes $(3,9957) 10^{\wedge} 6 / \mathrm{uL}$ were less than normal which had an impact on low Hb levels with the mean $(11,186) \mathrm{gr} / \mathrm{dL}$ indicating anemia. In another study, it was suggested that low $\mathrm{Hb}$ levels $(13 \mathrm{gr} / \mathrm{dL})$ in breast cancer were due to the effects of neoadjuvand treatment through antiproliferation inhibition[8].

One type of cytostatic drug Cisplatin causes damage to DNA through the intrastrand cross-linked DNA due tocontribution ROS, cytrocrom-c, JNK, p38MAPK, caspase[9]. This causes a decrease in hemoglobin and anemia due to the occurrence of death cell or development disorders of bone marrow cell, especially pathway of megakaryocyte erythrocyte progenitor followed by impaired erythroblast progenitor production, which causes a decrease in the number of reticulocytes and erythrocytes [10]

In this study, Table 2 showed increase levels of monocytes is high enough with mean $\left(10^{\wedge} 3 / \mathrm{uL}\right)$, this could be caused by factors carcinogenesis and metastasis of systemic inflammation as a side effect of cytostatic drugs. Monocytes are reticuloendothelial system, that circulating but non-phagocytes, then after a few hours in the cells develop into tissue macrophages.

There are many data that indicate the important role of the local immune response in carcinogenesis, but the systemic inflammatory response also seems to take part in this process[7], besides the concentration of C-reactive protein (CRP) and several cytokines (interleukin (IL) -1ra, IL-6, IL-7, IL-8, IL-9, IL-12, interferon $\gamma$, interferon $\gamma$-protein induced byll-10, monocyte chemotactic protein 1 , inflammatory macrophages of protein $1 \beta$ and platelet growth factors, and hypoalbuminemia, indirectly reflect the impact of immune system activity [10]. 
Shibutani et al (2017)., suggested that peripheral monocyte counts were positively related to the density of macrophages in tumors, and their correlated increase in value did not benefit the prognosis[11]. There is a hypothesis that shows that Cancer cells produce chemokines (such as CCL2) which recruit monocytes from peripheral blood to tumors [12], and will activate parts of monocytes from bone marrow to peripheral blood. Because cytokines present in the micro cancer environment (stimulating factors of macrophage colonies, the transformation of growth factor- $\beta$ (TGF- $\beta$ ), IL-6, and IL10 ), white blood cells differentiate into two macrophage phenotypes: antitumor M1 and procarcinogenic M2. The latter applies in the micro environment of tumors and produces vascular endothelial growth factor/angiogenic factors (VEGF) and tumor necrosis factor- $\alpha$ (TNF- $\alpha$ )) so they facilitate neoangiogenesis and matrix metalloproteinase in tumor cells.

Assessment and diagnosis in the nursing process is an input (stressor) based on the results of interviews, physical examinations and laboratory data. Problems arise if the adaptation system cannot respond and solve problems that caused by changes in the environment in an effort to maintain system integrity.

From this study expected that nurses who go through the critical-thinking process must be able to analyze data starting from the system level, organs, cells, and molecules/genes. Immunity indicator as a reference for nurses to be able to formulate problems accurately. Problems found can be accounted for scientifically. The final result of this stage was the identification of nursing problems, which were grouped into: (1) physical (biological); (2) psychological; (3) social; (4) spiritual.

\section{Conclusion and Suggestion}

The conclusion of this study was there were a decrease in erythrocytes, hemoglobin, hematocrit, and increase of monocytes in breast cancer patients undergoing chemotherapy treatment at the RSUP surgical polyclinic, Dr. Wahidin Sudirohusodo.

\section{References}

1. World Health Organization. 2014 [cited 2019 Feb 14]. Available from https://apps.who.int/iris/bitstream/handle/10665/112738/9789240692671 eng.pdf;jsessionid=11 3B0B78133E2D544D5F4D1B27C3AF48?sequence=1

2. Indonesian health profile. 2014. RI Ministry of Health [cited 2019 Feb 14]. Available from http://www.depkes.go.id/resources/download/pusdatin/profil-kesehatan-indonesia/profil-kesehatanindonesia-2014.pdf

3. Basic health research. 2013. Indonesian health ministry research and development body [cited 2019 Feb 14]. Available from http://www.depkes.go.id/resources/download/general/Hasil\%20Riskesdas\%202013.pdf

4. Zhu W, Xu B. Association of Pretreatment Anemia with Pathological Response and Survival of Breast Cancer Patients Treated with Neoadjuvant Chemotherapy: A Population-Based Study. 2015. PLoS ONE 10(8): e0136268. doi:10.1371/ journal.pone.0136268.

5. Barrett-Lee P, Bokemeyer C, Gascón P, NortierJ,Schneider M, Schrijvers D et. al., Management of cancer-related anemia in patients with breast or gynecologic cancer: new insights based on results from the european cancer anemia survey. 2005. The Oncol 10: 743-57.

6. Hemati S, Jolfaie NA, Abbas Gookizadeh, Rafenia M, Ghavamnasin R. The effects of vitamin E and selenium on cisplatin-induced nephrotoxicity in cancer patients treated with cisplatin-based chemotherapy: A randomized, pacebo-controlled study. 2012. J Res med sci 18(7): 626-7.

7. Caro JJ, Salas M, Ward A, Goss G. Anemia as an independent prognostic factor for survival in patients with cancer: a systemic, quantitative review. Cancer. 2001; 91:2214-2221. PMID: 11413508.

8. Boehm DU, Lebrecht A, Schmidt M, Siggelkow W, Lindner C, Litz A, et al. Prognostic impact of haemoglobin levels in breast cancer. Anticancer Res. 2007; 27:1223-1226. PMID: 17465267.

9. Fridman WH, Pages F, Sautes-Fridman C, Galon J. The immune contexture in human tumours: impact on clinical outcome. Nat Rev Cancer 2012; 12: 298-306.

10. Mantovani A, Allavena P, Sica A, Balkwill F. Cancer-related inflammation. Nature 2008; 454: 436-44.

11. Shibutani M, Maeda $\mathrm{K}$, Nagahara $\mathrm{H}$, et al. The peripheral monocytecount is associated with the density of tumor-associatedmacrophages in the tumor microenvironment of colorectal cancer:a retrospective study. BMC Cancer 2017; 17: 404. 
12. Szebeni GJ, Vizler C, Kitajka K, Puskas LG. Inflammation andcancer: extra- andintracellular determinants of tumor-associatedmacrophages as tumor promoters. Mediators Inflamm 2017; 2017: 9294018. 